\title{
Chondrocostal osteitis: an uncommon complication of gastrostomy tube placement
}

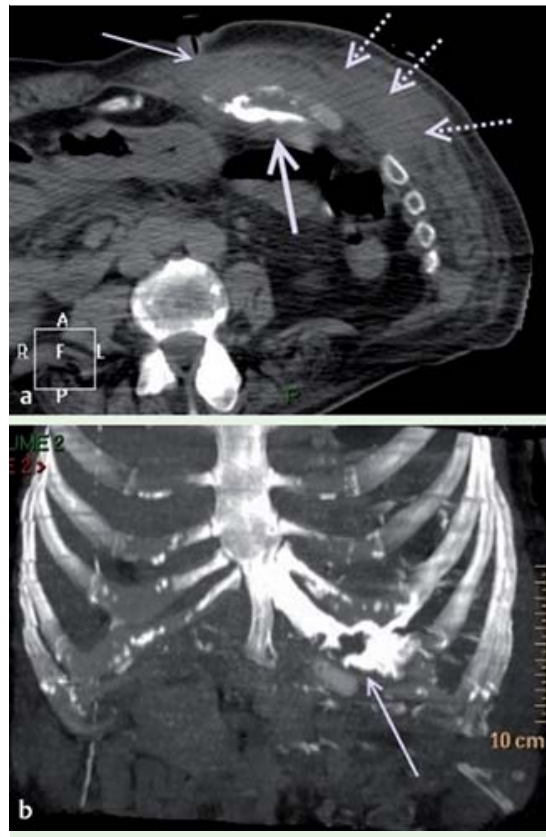

Fig. 1 Computed tomography (CT) scan of a 69-year-old patient with locked-in syndrome and infection from his gastrostomy. a Initial CT scan showed infiltration of the abdominal wall (dashed arrows) in direct contact with the gastrostomy (thin arrow), plus calcifications of the adjacent costal cartilages (thick arrow). b A 3-dimensional CT image reconstruction showed calcifications of the adjacent costal cartilages (arrow).

Percutaneous endoscopic gastrostomy (PEG) and percutaneous radiologically guided gastrostomy (PRG) can lead to infectious complications [1]. We report the first case of chondrocostal osteitis due to gastrostomy tube placement.

After a 10-year quiet period, a 69-year-old man with locked-in syndrome required five gastrostomy changes in 3 years. The most recent was performed under radiological guidance (PRG). He presented 3 months later with fever and abdominal pain and required hospitalization. He had peristomal inflammation with a purulent discharge around the tube. C-reactive protein (CRP) level was $154 \mathrm{mg} / \mathrm{L}$ without elevation of white blood cells (WBCs). Computed tomography (CT) scan showed infiltration of the abdominal wall in contact with the gastrostomy without hematoma or abscess but with calcifications of the adjacent costal cartilages ( $\bullet$ Fig. $\mathbf{1}$ a, b).

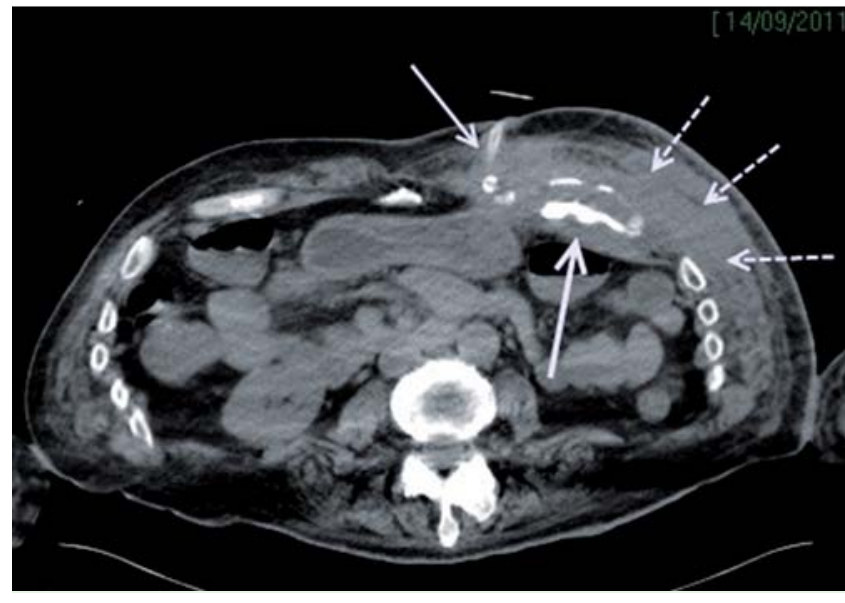

Fig. 2 The computed tomography scan 12 weeks after treatment showed no radiological evolution, with the persistence of the abdominal wall infiltration (dashed arrows) and signs of chondrocostal osteitis (thick arrow) in contact with the gastrostomy (thin arrow).

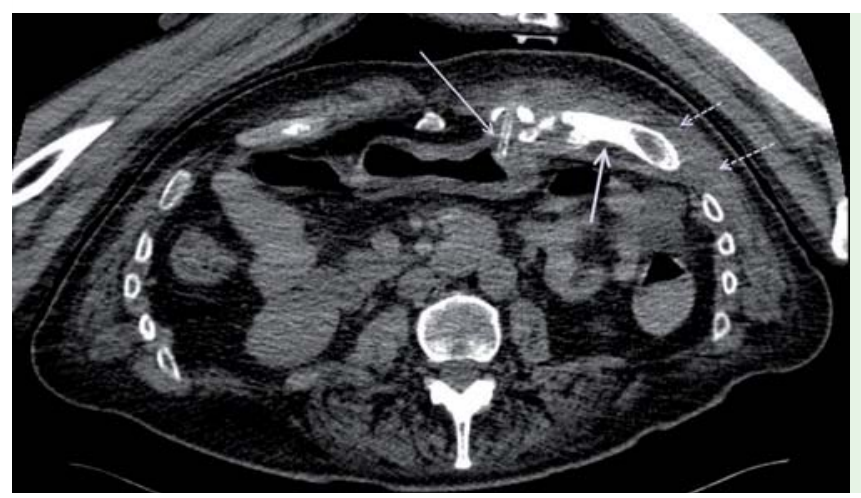

Fig. 3 The computed tomography scan 48 weeks after treatment showed an almost complete regression of edema and inflammation in the soft tissue compartment (dashed arrows) and stabilization of the chondrocostal lesions (thick arrow) in contact with the tube of the gastrostomy (thin arrow).

The samples from two punctures performed under CT scan were analyzed and results were positive for two distinct strains of coagulase-negative staphylococci, suggesting contamination. We hypothesized that the patient had a chondrocostal osteitis due to the gastrostomy. Although a single dose of antibiotic before PEG decreases the rate of infection in the short term [2], the benefit of antibiotic prophylaxis before PRG remains open to discussion [3].

We started probabilistic antibiotic therapy in our patient with ceftriaxone $2 \mathrm{~g} / \mathrm{d}$, ofloxacin $600 \mathrm{mg} / \mathrm{d}$, and metronidazole $1 \mathrm{~g} / \mathrm{d}$ to target Gram-negative bacilli, anaerobes, and staphylococcus. A blood culture containing methicillin-susceptible Staphylococcus aureus was justification to switch to ofloxacin $600 \mathrm{mg} / \mathrm{d}$ and rifampicin $900 \mathrm{mg} / \mathrm{d}$. The course of the disease was favorable and we decided not to per- form rib removal in this high-risk surgical patient.

After 4 weeks of antibiotic therapy, the patient had no sign of infection and a normalized biological balance (CRP $26 \mathrm{mg} / \mathrm{L}$, WBC $5900 / \mathrm{mm}^{3}$ ). The CT scan was unchanged after 4-12 weeks ( Fig. 2). We decided to stop antibiotic therapy after 12 weeks in accordance with the guidelines issued by the Infectious Diseases Society of America for bone and joint infection on prosthesis [4].

After 48 weeks, the CT scan showed major improvement ( $\mathbf{F i g . 3}$ ). After 1 year, medical treatment, without surgery, had proved to be effective.

Endoscopy_UCTN_Code_CPL_1AH_2AI

Competing interests: None 


\section{B. Davido ${ }^{1,2}$, C. Rouzaud ${ }^{1}$, M. Hanachi ${ }^{3}$,} P. De Truchis ${ }^{1}$, A. Dinh ${ }^{1}$, C. Perronne ${ }^{1,2}$

${ }^{1}$ Infectious Diseases, Raymond Poincaré Teaching Hospital, Garches, France

2 Université de Versailles Saint Quentin-enYvelines, Montigny Le Bretonneux, France

${ }^{3}$ Nutrition Department, Raymond Poincaré Teaching Hospital, Garches, France

\section{References}

1 Cosentini EP, Sautner T, Gnant M et al. Outcomes of surgical, percutaneous endoscopic, and percutaneous radiologic gastrostomies. Arch Surg 1998; 133: 1076-1083

2 Barthet M, Napoleon B, Gay G et al. Antibiotic prophylaxis for digestive endoscopy. Endoscopy 2004; 36: $1123-1125$

3 Preclik G, Grüne S, Leser HG et al. Prospective, randomised, double blind trial of prophylaxis with single dose of co-amoxiclav before percutaneous endoscopic gastrostomy. BMJ 1999; 319: $881-884$

4 Osmon DR, Berbari EF, Berendt AR et al. Executive summary: diagnosis and management of prosthetic joint infection: clinical practice guidelines by the infectious diseases society of America. Clin Infect Dis 2013; 56: $1-10$

\section{Bibliography}

Dol http://dx.doi.org/

10.1055/s-0033-1344562

Endoscopy 2013; 45: E259-E260

(c) Georg Thieme Verlag KG

Stuttgart · New York

ISSN 0013-726X

\section{Corresponding author}

\section{B. Davido, MD}

Infectious Diseases Department Raymond Poincaré Teaching Hospital

Garches 92380

France

Fax: +33-1-47107790

benjamin.davido@rpc.aphp.fr 